\title{
FACTORS INFLUENCING THE INTENTION TO USE THE ELECTRONIC LOGISTICS INFORMATION SYSTEM IN HOSPITALS IN NORTHERN AND CENTRAL VIETNAM
}

\author{
Trinh Thi Thu-Huong ${ }^{1 *}$, Tran Nhat-Thuy ${ }^{1}$, Nguyen Thi-Na $^{1}$, Nguyen Hien-Anh $^{1}$, \\ Nguyen Duc-Thinh ${ }^{1}$ and Pham Tran Kieu-Trinh ${ }^{1}$ \\ ${ }^{1}$ Foreign Trade University, Vietnam
}

\begin{abstract}
Purpose: The cost of healthcare has always been high in Vietnam, causing considerable difficulties for citizens to access to good quality medical services. Cutting operating cost in hospitals through an efficient management becomes more and more urgent. The electronic logistics information system (ELIS) is preferable to reduce operating expenses and improve efficiency in Vietnamese hospitals. This study aims to find out which factors having impact on hospital employees' intention to use of the ELIS in Northern and Central Vietnam so performance of ELIS could be improved in Vietnamese hospitals.
\end{abstract}

Method: To observe medical staff's acceptance, we utilized a quantitative method with survey conducted across wide sample of Northern and Central Vietnam, estimate the causal model by structural equation modeling technique and inspect the reliability and validity of the measurement model through performance of exploratory and confirmatory factor analysis.

Findings: This study shows that perceived ease of use, perceived usefulness and compatibility positively affecting the intention of medical staff in Northen and Central Vietnam to use ELIS.

Keywords: electronic logistics information system (ELIS), technology acceptance model (TAM), diffusion of innovation theory (DOI), hospitals.

\section{Introduction}

In recent years, the rapid development of information technology (IT) has had big impacts on many industries and brought lots of benefits to both economic and social sectors. According to the statistic released by Internet World Stats, by December 31, 2017, the world total number of Internet users was more than 4 billion, accounting for $54.4 \%$ of the world total population. For this reason, e-services are widely accepted among enterprises, including healthcare sector.

In hospitals, expenditure for capital management, human resource management and patients' records management accounts significantly (Protil et al., 2002). Electronic information system, which processes large amounts of hospital information and daily work, and helps avoid repetition and damage from lack of rationalization, is necessary to set up an economical management system.

Poulin (2003) stated that more than $30 \%$ of the total hospital expenditures were invested in logistics activities, and such cost would be reduced by half if these activities were effectively managed. The improvements in hospitals supply chain may enhance the management of operating rooms, medication and inventory, improve relationship with suppliers, raise patient satisfaction and boost working efficiency for hospital staff (Burt, 2006). Hospital executives are seeking for a practical management method simplifying hospital logistics system and facilitating information flow at a minimal cost. ELIS, which is both time-saving and cost-effective, is considered as a solution to improve hospital supply chain management (Tung et al., 2008) and thus to reduce overall hospital management expenditure. 
Vietnam hospitals are coping with reducing financial costs pressure. Hospital executives are seeking for a practical management method simplifying hospital logistics system and facilitating information flow at a minimal cost. Applying ELIS into hospital management activities and treatment for patients to save costs has recently taken place as a new trend with increasing level of application. Besides, while most researches on IT concentrate either on the technology sector, or on manufacturers and electronics (Tung et al., 2008), very few studies relate to the operation in hospitals. In order to put this system into service, hospitals' managers need to understand the factors that have impacts on behavioral intention to use ELIS of medical staff. This study employs a research model of Tung et al. (2008) to examine factors affecting the intention to use the ELIS in hospitals in Northern and Central Vietnam. The research model is the combination of TAM and the DOI, trust, and perceived financial cost.

While widespread TAM and DOI have been relatively generally used to investigate technology adoption in Vietnam, trust and perceived financial cost have been rarely conducted. TAM was employed to analyze the adoption of mobile devices and smartphones among Vietnamese students (Khanh and Gim, 2014). Nguyen et al. (2016) conducted DOI to identify the determinant of adoption in cloud computing in Vietnam. Hwang et al. (2009) analyzed the diffusion of mobile telecommunications services in Vietnam based on logistic DOI framework. Lam et al. (2004) utilized DOI to explore the techno-economic factors that determined the diffusion of the Internet in Vietnam. Those findings were approvingly recognized to be consistent with previous studies. Are trust and perceived financial cost favorably supported in the context of Vietnam?

\section{Theoretical background and hypothesis}

\section{Electronic logistics information system (ELIS)}

In hospitals, an extensive amount of information is collected from goods flow and patient flow. Goods flow within hospitals consists of 3 main activities: Purchasing, Inventory, Internal Distribution (Protil et al., 2002). Purchasing provides information on re-supplying request, stock orders and transportation documents. Inventory restores information on storage house in-and-out flow. Internal distribution refers to the transportation of hospitals' materials between storage areas and points of care (Landry and Philippe, 2004), hence releasing information on usage level of different wards and transportation information. Some examples of information gathered from patient flow are patient records, medical tests' results, billing and insurance information.

To deal with such huge amount of information, a practice called Logistics information systems (LIS) is increasingly used (Rutner et al., 2003). LIS is simply a combination of logistics and Information System (IS) in which IS aims at collecting, categorizing, storing and providing relevant information needed to decision makers, and logistics focuses on design, implementation and control of efficient flows, storage of goods or services. Therefore LIS is defined as "an interacting structure of people, equipment and procedures which together make relevant information available to the logistics manager for the purposes of planning, implementation and control" (Lang et al., 1995).

There are 2 types of approaches toward LIS (Tung et al., 2008). Traditional approach heavily relies on paperwork. Its drawbacks include slow and error-prone information exchange, and waste in organization's resources in terms of storage and labor. By means of technology development and the bloom of Internet worldwide, ELIS has now emerged as an efficient way to manage logistics information (Tung et al., 2008). Some of the electronic applications integrated in healthcare system are data analyses, computerized medical records, video/fax transmissions and robotics. (Johns, 1997). 


\section{Technology Acceptance Model (TAM)}

TAM model was originated from The Theory of Reasoned Action (TRA) (Fishbein and Ajzen, 1975) in which Fishbein and Ajzen suggested that the actual behavior of a person is directly influenced by his intention to perform such behavior. It, in turn, is determined by the attitude toward the action (A) and the subject norms (SN). There are 2 types of belief that lie behind A and SN which are, respectively, salient belief and normative belief. Davis (1985) adopted TRA model in explanation for the user's acceptance of certain IT, based on the idea that the actual use of a system is a behavior. However, he eliminated SN construct out of the model and narrowed down the salient belief into Perceived Usefulness (PU) and Perceived ease of use (PEOU).

In the final version of TAM (Davis and Venkatesh, 1996), PU and PEOU were found to be influenced by the external variables, and to have direct and positive effects on one's intention to use, which in turn led to the actual use of the system. The results also indicated that PEOU exerted a significant and positive influence on PU. The positive relationships between PU and PEOU and between PU, PEOU and the intention to use were found in many other empirical researches, such as in the papers of Agarwal and Karahanna (2000), Gefen (2004), Gefen et al. (2003), Pavlou (2003), Saeed et al. (2003), Wu and Chen (2005), etc. Some important models developed from TAM include TAM2 (Venkatesh and Davis, 2000) and Unified Theory of Acceptance and Use of Technology (UTAUT) (Venkatesh et al., 2003).

TAM is now a leading model in explaining and predicting the use of a system for its simplicity and ease of implementation yet effectiveness (Chuttur, 2009). However, TAM is not a model specifically established for the healthcare's technology. Since healthcare is a rather specialized sector, the generic measures used in TAM may not hold the same applicability and effectiveness in healthcare context as in others (Melas et al., 2011). However, there are only few replication studies of TAM in healthcare. Holden and Karsh (2010), in their review, found 22 researches on health IT using TAM and related model as the framework. These researches focused on a wide range of health IT but none studied ELIS. In Vietnam, there is no study of the usage of ELIS up to date. Therefore, we used TAM in our quantitative analysis with a view to testing whether TAM is a fitting theory for one's intention to use ELIS in Vietnam.

\section{Diffusion of innovation theory}

The diffusion of innovation theory (DOI) developed by Rogers (1962) seeks to explain how, why, and at what rate innovations spread. Rogers (1995) indicated that "innovation" was comparable to invention related to technology which comprised computer hardware and software. Diffusion of innovation theory has been widely used for researches related to IT and IS (E. Karahanna, 1999).

Diffusion is "the process by which an innovation is communicated through certain channels over time among the members of a social system" (Rogers, 1983). According to Rogers (1983), diffusion occurred through a fivestep decision making process comprising knowledge, persuasion, decision, implementation and confirmation. In the persuasion stage, potential adopters, who had knowledge about innovation, evaluated an innovation through their perceived characteristics of innovation (PCI) to decide whether to adopt innovation. Those PCI consisted of relative advantage, compatibility, complexity, trial ability and observability (Rogers, 1983).

The diffusion was difficult to quantify due to the complication of humans and social network. Therefore it should be appraised with severe measurement so that factors causing innovation acceptance, especially in healthcare sector, could be identified (Plsek and Greenhalgh, 2001). Innovation theory and theory of barriers to innovation were combined to analyze the challenge in picture archive and communication systems execution in hospitals (Paré and Trudel, 2007). These literature shows appropriateness of DOI in examining technology acceptance behavior in general and also in health care 


\section{Relationship between TAM and DOI}

After an extensive literature review, Tornatzky and Klein (1982) conclude that relative advantage, compatibility and complexity are the most relevant constructs to adoption research. Two IDT's remaining elements which were trial ability and observability had no strong correlations to users' attitude toward IT adoption (Agarwal, 1998). According to Tung et al. (2008), there was a relationship between the DOI and TAM. Particularly, relative advantage (from IDT) was comparable to PU (from TAM), complexity (from IDT) correlated to PEOU (from TAM) (Moore and Benbasat, 1991) and compatibility (from IDT) had positive impacts on intention to use (Tung et al., 2008).

Moore and Benbasat (1991) explained that to develop TAM, Davis evaluated various scales of PCI including 5 PCI in DOI. He therefore built PU and PEOU constructs based on elementary ideas of "relative advantage" and "complexity" constructs in DOI. PU and PEOU instrument development of previous constructs with higher reliability (>0.90 for each).

Chen et al. (2002) combined the original TAM and "compatibility" construct in the DOI to measure and explain customer behavior in the context of virtual stores. Wu and Wang (2005) integrated IDT and perceived risk and cost into the TAM to examine the determinants of mobile commerce adoption. They found "compatibility" had a direct impact on the PEOU and intention to use. Wu et al. (2007) integrated the TAM with three factors: compatibility, mobile healthcare system self-efficacy, technology support and training to model healthcare professionals' acceptance of the mobile healthcare system. Results showed that high compatibility led to acceptable adoption. Horan et al. (2004) integrated TAM and compatibility in work practice to examine physicians' acceptance of an online disability assessment system. Results showed that compatibility was an important factor in predicting behavioral intention.

\section{Trust and TAM}

Morgan and Hunt (1994) defined trust as the perception of "confidence in the exchange partner's reliability and integrity". Doney et al. (1998) defined "trust" as "the measure of belief and goodwill that feel in and for, trusted people". Garbarino and Johnson (1999) stated that trust is the confidence of customers in the quality and reliability of the service provided by an organization. In trading, trust can also be defined as the tendency to rely on a trusted trading partner. Similar to widely used PU and PEOU constructs in TAM, trust is also important for e-commerce systems acceptance (Gefen et al., 2003a, 2003b).

Pavlou (2003), Saeed, et al. (2003) and Gefen (2004) implied that the correlation between trust and TAM was reflected in the relationship between PU, PEOU and trust. Wu and Chen (2005) stated that trust was the antecedent of PU, PEOU was the antecedent of trust, and trust had a direct impact on the intention to use. Gefen (2004) stated that relationship between customers and the suppliers increased significantly due to their trust in suppliers and properties of the technology itself, especially its usefulness. Also, trust has positive effect on PU as trust allows consumers to become vulnerable to e-vendor to ensure that they gain the expected useful interaction and service (Pavlou, 2003). On the other hand, PEOU has a direct and positive impact on trust in the online shopping market (Gefen et al., 2003a, 2003b) because PEOU helped promote customers' favorable impression on e-vendors in the initial adoption of online service and further, therefore customers would be willing to made investment and commitment in buyer-seller relationship Ganesan (1994). Garbarino (1999) argued that trust and commitment are most significant determinants on the intention of long-term customers.

Smith (2004) argued that if the electronic drug system succeeded not to impair customers' trust, online drug suppliers would satisfy conditions customers required, thereby obtaining customers' loyalty and retention. In the pharmaceutical industry, the adoption of electronic prescriptions would be challenged with barriers including lack of trust in technology, system costs and risks of leakage of patient health and drug information (Smith, 
2006). Trust was an important variable influencing the intention to use electronic information systems, especially in hospitals (Tung, et al., 2008). In Vietnam, there were studies examining impacts of trust in technology adoption in some sectors but healthcare sector. We propose to examine whether previous hypothesis of trust in technology acceptance is a proper explanation in practical conditions of Vietnamese healthcare sector.

\section{Perceived financial cost and TAM}

Perceived financial cost is the extent to which a person feels it is costly to use an electronic information system in a logistics operation. According to Mathieson et al. (2001), perceived financial resources was an important determinant on the intention to use information systems. Luarn and Lin (2005) stated that perceived financial cost had a negative impact on intention to use mobile banking. In the context of popular e-commerce on the mobile platform, many consumers still refuse to use mobile banking due to cost considerations, or lack of knowledge and skills needed (Luarn and Lin, 2005). In the healthcare sector, Smith (2006) argued that the cost of information systems was one of the barriers to e-prescription acceptance. On studying the barriers to adopt handheld computers in medical sector, Lu et al. (2005) stated that lack of funding for the devices and software applications was one of numerous barriers that could discourage PDA adoption by clinicians. "E-prescribing is a tough sell to physicians because it requires them to absorb the full cost of a technology that benefits everyone but them" (Chin, 2003a, 2003b). Tung (2008) also combined PFC with TAM model to study factors influencing adoption of ELIS in Taiwan medical industry. According to those researches, PFC has negative impact on behavioral intention to use ELIS. Further more, in Vietnam, few studies were conduct to investigate how cost influences intention to use technology in any sector. Thus, PFC is added in our research model to examine how it influences BI of ELIS in Vietnamese context.

\section{Research model and hypothesis}

Based on the recent actual conditions of Vietnam, the above theoretical models (theory of reasoned action, theory of planned behavior, TAM, DOI) and by replicating TAM hybrid model (Tung, 2008), we studied 5 factors, including perceived financial cost (PFC), compatibility (C), perceived usefulness (PU), perceived ease of use (PEOU) and trust (T) to find out what factors are significant in shifting the behavioral intention to use, and to evaluate the extent to which these factors have impacts on hospital employees' acceptance of ELIS. We, therefore, established a research model, which is shown in Figure 1 and nine hypotheses, which are shown in Table 1.

Table 1. Hypothesis of the research model

\begin{tabular}{lll}
\hline Construct & Hypotheses & Reference \\
$\begin{array}{l}\text { Perceived } \\
\text { financial cost } \\
\text { (PFC) }\end{array}$ & $\begin{array}{l}\text { H1: Perceived financial cost will have a negative effect in } \\
\text { behavioral intention to use electronic Logistics information } \\
\text { system. }\end{array}$ & $\begin{array}{l}\text { Tung } \text { et al. (2008), Luarn and Lin } \\
\text { (2004), Lu } \text { et al. (2005), Smith } \\
\text { (2006), Mathieson } \text { et al. (2001) }\end{array}$ \\
\hline Compatibility (C) & $\begin{array}{l}\text { H2: Compatibility will have a direct effect on behavioral } \\
\text { intention to use electronic Logistics information system. }\end{array}$ & $\begin{array}{l}\text { Taylor and Todd (1995), Wu and } \\
\text { Wang (2005), Wu } \text { et al. (2007), } \\
\text { Taylor and Todd (1995) }\end{array}$ \\
& $\begin{array}{l}\text { H3: Compatibility will have a direct effect on perceived } \\
\text { usefulness to use electronic Logistics information system. }\end{array}$ & \\
\hline $\begin{array}{l}\text { Perceived } \\
\text { usefulness (PU) }\end{array}$ & $\begin{array}{l}\text { H4: Perceived usefulness will have a positive effect on } \\
\text { behavioral intention to use electronic logistics information } \\
\text { system }\end{array}$ & $\begin{array}{l}\text { Agarwal and Karahanna (2000), } \\
\text { Gefen (2004), Gefen } \text { et al. (2003), } \\
\text { Perceived ease of }\end{array}$ \\
use (PEOU) & $\begin{array}{l}\text { H5: Perceived ease of use will have a positive effect on } \\
\text { perceived usefulness of electronic logistics information }\end{array}$ & $\begin{array}{l}\text { Saeed } \text { et al. (2003), Wu and Chen } \\
\text { (2005) }\end{array}$ \\
& $\begin{array}{l}\text { system. } \\
\text { H6: Perceived ease of use will have a positive effect on } \\
\text { behavioral intention to use electronic logistics information } \\
\text { system. }\end{array}$ & \\
\hline
\end{tabular}


H7: Perceived ease of use will have positive effect on trust in electronic logistics information system.

Trust (T)
H8: Trust will have a positive effect on behavioral intention to use electronic logistics information system.

H9: Trust will have positive effect on perceived usefulness to use electronic logistics information system
Gefen (2004), Gefen et al. (2003), Pavlou (2003), Saeed et al. (2003), Karahanna et al. (1999)

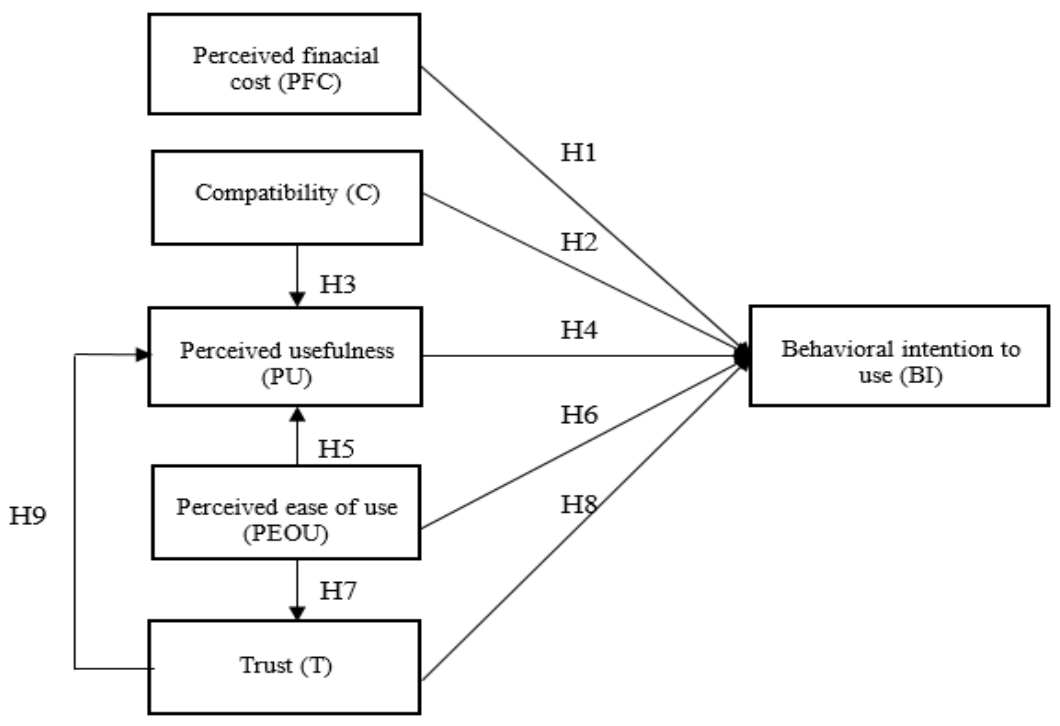

Figure 1. Research model

\section{Methodology}

\section{Instrument development}

The instrument is a three-part questionnaire. The first part and the third part uses nominal scales and the second part uses seven-point Likert scales. Part 1 includes questions acquiring information about which equipment is utilized for ELIS and actual ELIS usage status in hospitals. Part 3 contains questions obtaining basic information about the respondents. Part 2 contains 18 items of 6 constructs of this study's model. Compatibility construct is measured by three items built by Wu and Wang (2005). Each of PU and PEOU is adapted from the four-item measurement defined by Venkatesh and Davis $(1996,2000)$. Trust construct is measured by three items adapted from Gefen et al. (2003). Perceived financial cost construct is adapted from two-item measurement of Luarn and Lin (2005). Construct of behavioral intention to use is adapted from two-item measurement Venkatesh and Davis $(1996,2000)$. All scale items are given in Table 2.

Table 2. Measurement items and pattern matrix

\begin{tabular}{lllll}
\hline Construct & Items & \multicolumn{4}{c}{ Component } \\
\cline { 2 - 4 } PU & $\begin{array}{l}\text { Using electronic logistics information system can } \\
\text { improve my work efficiency }\end{array}$ & .92 & 3 & 5 \\
\hline & $\begin{array}{l}\text { Using electronic logistics information system would } \\
\text { enhance my job performance }\end{array}$ & .88 & \\
& $\begin{array}{l}\text { Using electronic logistics information system would } \\
\text { increase my productivity }\end{array}$ & .88 & \\
& I find electronic logistics information system is & .80 & \\
\end{tabular}




\begin{tabular}{|c|c|c|c|c|c|c|}
\hline & useful for my work & & & & & \\
\hline \multirow[t]{4}{*}{ PEOU } & $\begin{array}{l}\text { It is easy to operate electronic logistics information } \\
\text { system and do anything that I want it to do }\end{array}$ & .90 & & & & \\
\hline & $\begin{array}{l}\text { I find that electronic logistics information system is } \\
\text { very easy to use }\end{array}$ & .89 & & & & \\
\hline & $\begin{array}{l}\text { I find that the human interface of electronic logistics } \\
\text { information system is clear and easy to understand }\end{array}$ & .76 & & & & \\
\hline & $\begin{array}{l}\text { I find that interacting with electronic logistics } \\
\text { information system does not demand much care and } \\
\text { attention }\end{array}$ & .73 & & & & \\
\hline \multirow[t]{3}{*}{$\mathrm{C}$} & $\begin{array}{l}\text { Using electronic logistics information system is } \\
\text { compatible with most aspects of my work }\end{array}$ & & .90 & & & \\
\hline & $\begin{array}{l}\text { Using electronic logistics information system is } \\
\text { suitable for my work style }\end{array}$ & & .90 & & & \\
\hline & $\begin{array}{l}\text { Using electronic logistics information system is } \\
\text { suitable for my life style }\end{array}$ & & .75 & & & \\
\hline \multirow[t]{2}{*}{ BI } & $\begin{array}{l}\text { If I get access to an electronic logistics information } \\
\text { system, I intend to use it }\end{array}$ & & & 1.07 & & \\
\hline & $\begin{array}{l}\text { If I get access to an electronic logistics information } \\
\text { system, I expect that I will use it }\end{array}$ & & & .95 & & \\
\hline \multirow[t]{2}{*}{$\mathrm{PFC}$} & $\begin{array}{l}\text { I think the equipment required to deploy electronic } \\
\text { logistics information system is expensive }\end{array}$ & & & \multicolumn{3}{|c|}{.91} \\
\hline & $\begin{array}{l}\text { I think it costs a lot to learn electronic logistics } \\
\text { information system }\end{array}$ & & & \multicolumn{3}{|c|}{.88} \\
\hline \multirow[t]{3}{*}{$\mathrm{T}$} & $\begin{array}{l}\text { As I understand it, electronic logistics information } \\
\text { system will have its anticipated effects }\end{array}$ & & & & & .95 \\
\hline & $\begin{array}{l}\text { As I understand it, electronic logistics information } \\
\text { system provides very good functionalities }\end{array}$ & & & & & .57 \\
\hline & $\begin{array}{l}\text { As I understand it, I believe electronic logistics } \\
\text { information system can help employees' work }\end{array}$ & & & & & $<0.5$ \\
\hline
\end{tabular}

\section{Sample organizations and respondents}

To test the research model, we collected data from 25 hospitals that have used ELIS (yielding a rate of $3.85 \%$ of total 648 hospitals) in Northern and Central Vietnam based on the quota sampling method. The target population is doctors, nurses, technicians and administrative staff. As to the distribution of questionnaires, we directly went to all 25 hospitals for the measurement of immediate release and collection of questionnaires. A survey was distributed to 500 respondents and 408 were returned, yielding a response rate of $81.60 \%$. From the 408 answer sheets we collected, we excluded 43 that were incomplete, leaving a total of 365 valid.

Out of 310 respondents answering the gender question, the number of women doubled that of men. About half of respondents $(51.63 \%$ ) was below 30 year old while $35.77 \%$ respondents were between 30 and 40 year old and the remaining was older. Concerning the position of respondents in the hospitals, nurses made up for the largest share of $44 \%$, doctors accounted for $22 \%$, technicians took up $16 \%$, office workers accounted for $13 \%$ and the remaining $(4 \%)$ performed other duties in the hospital. Our survey was implemented in three regions of Vietnam: 58.08\% of the respondents worked in hospitals in Red River area, while this rate was $30.41 \%$ and $11.51 \%$ in North Central and Central Coast of Vietnam area and in Midland and mountainous North of Vietnam area respectively. Out of 25 investigated hospitals, only one was private and 24 others was public. The biggest share of $46.22 \%$ of the respondents used the electronic logistic information system for less than 2 years while $28 \%$ of respondents used for $2-4$ years, and the rate was $16.44 \%, 9.33 \%$ for $4-6$ years and $6-8$ years accordingly. 
Almost all of the surveyed hospitals (more than 90\%) used computers, applications and the Internet for logistic activities. A large quantity of the hospitals (44\%) had new technology medical equipment supporting their logistic system in their hospitals.

The survey revealed that the ELIS was used widely for keeping patient records (92\% of the examined hospitals did) as well as medical staff data ( $100 \%$ of the hospitals did). There was more than $70 \%$ of the hospitals making use of the system for tracking input and output, distributing supplies for departments and it also played as the Intranet. Nevertheless, only a minority of the hospitals (6 out of 25 hospitals) applied the electronic logistic information system into processing and recycling medical waste.

\section{Method of data analysis}

Four statistical methods were employed for our data analysis, including cronbach's alpha test, confirmatory factor analysis (CFA), exploratory factor analysis (EFA) and structural equation model (SEM).

First, Conbach's alpha was conducted to assess the reliability of scales based on the collected data. Nunnally (1978) suggested that the variable with corrected items-total correlation less than 0.3 be removed, and that the scale be reliable if the Cronbach's alpha was greater than 0.7 .

We then used CFA to evaluate how well our constructed model fits the dataset. The assessment was based on seven model-fit measures, namely the ratio of Chi-square $(\chi 2)$ to degrees-of-freedom (d.f.), goodness-of-fit index (GFI), normalised fit index (NFI), non-normalised fit index (NNFI), comparative fit index (CFI), root mean square error of approximation (RMSEA), and root mean square residual (RMSR). Construct validity was further tested in terms of convergent validity and discriminant validity.

After CFA, EFA was used to extract new latent variable structure from the garnered data. EFA differs from CFA in a way that EFA's purpose is to determine the underlying factor structure without any constraint on the outcome (Child, 1990). In CFA, researchers often have to demonstrate sufficient literature background supporting the research model (Furr, 2011). In contrast, EFA has no requirement of a priori theory, allowing researchers to generate the model from the explored latent variable structure. (Williams et al., 2010). When the theoretical model is not confirmed by CFA, EFA is used as the follow-up (Suhr, 2006). EFA assists in determining the number of factors in order to establish a more suitable model.

In our paper, factor extraction follows three stages as mentioned below. We first used the correlation between factors the model, KMO test and Bartlett test to determine whether the given data are suitable for EFA analysis. The correlation between factors is measured by loading factor. According to Hair et al. (2009), loading factors should be greater than 0.5, KMO test being within the range of 0.5, and Barlett's test significance being below 0.05. Next, we determined the factor extraction and loading structure. Items were rotated by promax rotation to group them into factors. In the last stage, we performed CFA again to establish the extracted model's validity and supporting indices.

Finally, we adopted SEM to examine the causal relationships among latent constructs, using the maximum likelihood estimation (MLE). Our data satisfy the requirement for MLE of sample size of at least 200 (Boomsma, 1983). Univariate kurtosis and univariate skewness of each indicator variable were within the acceptance range set forth by (West et al., 1995) (kurtosis $<7$ and skewness $<2$ in absolute value), except for items B1 (skew = 2.058; kurtosis = 7.162) and B2 (kurtosis = 7.773) slightly deviating from the required value. Further, since the focus of our study is on the significance of the path coefficients rather than on the actual parameters, abnormality in our data does not affect the analysis (Bolt, 1999). 


\section{Results}

\section{Analysis of the measurement model}

1. Confirmatory factor analysis (CFA)

Cronbach's alpha is used to evaluate the content validity. Collected data are analyzed by SPSS version 20 and AMOS version 25 software. Items for each construct, as we followed Tung et al.'s (2008) model, are shown in Table 3. Cronbach's alpha reliability coefficient for $\mathrm{C}$ is 0.90 , PU 0.94, PEOU 0.87, T 0.860, PFC 0.75 and BI 0.90. The result of a reliability analysis shows that the Cronbach's Alpha value of the scales is high (greater than 0.7) as suggested by Nunnally (1978). Hence, the scale could be reliable.

Table 3. Cronbach's $\alpha$, construct reliability, convergent and discriminant validities of measurement model

\begin{tabular}{|c|c|c|c|c|c|c|c|c|c|c|}
\hline \multirow{2}{*}{ Construct } & \multicolumn{6}{|c|}{ Factor Correlations } & \multirow{2}{*}{$\begin{array}{c}\text { Cronbach's } \\
\alpha\end{array}$} & \multirow{2}{*}{$\mathrm{CR}$} & \multirow{2}{*}{ AVE } & \multirow{2}{*}{ Item loading $(\boldsymbol{\lambda})$} \\
\hline & $\mathrm{C}$ & PU & PEOU & $\mathrm{BI}$ & PFC & $\mathrm{T}$ & & & & \\
\hline $\mathrm{C}$ & 1.00 & & & & & & 0.90 & 0.90 & 0.76 & $0.62-0.91$ \\
\hline PU & 0.59 & 1.00 & & & & & 0.94 & 0.94 & 0.81 & $0.86-0.92$ \\
\hline PEOU & 0.52 & 0.43 & 1.00 & & & & 0.87 & 0.88 & 0.65 & $0.80-0.95$ \\
\hline BI & 0.65 & 0.47 & 0.55 & 1.00 & & & 0.90 & 0.90 & 0.82 & $0.87-0.94$ \\
\hline PFC & 0.05 & -0.02 & -0.01 & 0.15 & 1.00 & & 0.75 & 19.54 & 31.27 & $0.08-7.91$ \\
\hline $\mathrm{T}$ & 0.54 & 0.58 & 0.62 & 0.59 & 0.08 & 1.00 & 0.86 & 0.86 & 0.68 & $0.72-0.88$ \\
\hline
\end{tabular}

Results of model's overall goodness-of-fit from analysing the surveyed data with AMOS version 25 software show that the main conceptual model has high fitness indices. Results are summarized in table 4. The Chisquare for the measurement model is calculated and found to be $487.97(\mathrm{P}=0.00)$ with 120 d.f. The ratio of Chisquare to degrees of freedom $(\chi 2 /$ d.f $)$ is 4.07 , which is less than 5, as recommended by Wheaton et al. (1977). The value of NFI is $0.91(>0.9)$, NNFI $0.91(>0.9)$, and CFI $0.93(>0.9)$. The RMSEA and RMSR are 0.09 and 0.08 respectively, which are within the acceptable range $(<0.1)$ suggested by MacCallum et al. (1996). The GFI (0.87), although slightly different from the advocated benchmark $(>=0.9)$, is still acceptable. Therefore, most fit indices meet the required values, representing a proper fit between the data and the proposed measurement model.

Table 4. Goodness-of-fit measures of research model

\begin{tabular}{|l|c|c|c|}
\hline Fit indices & Recommended value & Result value (6-factor model) & Result value (4-factor model) \\
\hline$\chi 2$ & N/A & 487.97 & 277.79 \\
\hline d.f & N/A & 120 & 59 \\
\hline$\chi 2 /$ d.f & $\leq 5.0$ & 4.07 & 4.71 \\
\hline GFI & $\geq 0.9$ & 0.87 & 0.90 \\
\hline NFI & $\geq 0.9$ & 0.91 & 0.93 \\
\hline NNFI & $\geq 0.9$ & 0.91 & 0.93 \\
\hline
\end{tabular}




\begin{tabular}{|l|l|l|l|}
\hline CFI & $>0.9$ & 0.93 & 0.95 \\
\hline RMSEA & $<0.1$ & 0.09 & 0.10 \\
\hline RMSR & $<0.1$ & 0.08 & 0.07 \\
\hline
\end{tabular}

Convergent validity was examined using 3 criteria, item loading $(\lambda)$, composite reliability (CR) and average variance extracted (AVE). Item loading and composite reliability should be equal to or greater than 0.7 and 0.8 respectively; a recommended AVE value for an adequate convergent validity is larger than 0.5 (Fornell and Larcker, 1981). Results of convergent validity are reported in Table 3. Item loading ( $\lambda$ ) for C, PU, PEOU, T, and BI varies between 0.72 and 0.95 (>0.7) (except that of PEOU4) with P-value of 0.01. CR of C, PU, PEOU, T and $\mathrm{BI}$ is greater than 0.8 as recommended, and AVE of them ranges from 0.65 to $0.82(>0.5)$. There is only an abnormality in these values of PFC.

Discriminant validity is established if the square correlation between the construct and other contructs in the research model is smaller than its AVE (Fornell and Larcker, 1981). Results reveal that, except for AVE of PFC, the AVE of the remaining constructs meet the requirements (Table 3). This study, therefore, designates great discriminant validity of the proposed measurement model.

\section{Exploratory factor analysis (EFA)}

An exploratory factor analysis (EFA) was conducted with 6 latent constructs to assess its construct validity. The KMO value for this study of $0.90(0.5<0.90<1)$ confirms the adequacy of the sample. Bartlett's Test of Sphericity has the significance of less than 0.001 . Consequently, EFA is suitable for the collected data.

Factors are extracted with principal component analysis. Criteria for determining the factor extraction includes Kaiser's criterion and cumulative percentage of variance. Kaiser's criterion suggested the acceptance of factors with eigenvalue $>1$ (Nunally, 1978). Premised on this rule, four factors for our model were accepted (compatibility, perceived ease of use, perceived usefulness and behavioral intention to use) while we excluded perceived financial cost and trust (Table 5). The cumulative percentage of variance for our research is $49.07 \%$, which is accepted for humanities (Pett, 2003).

Table 5. Total Variance Explained

\begin{tabular}{|l|c|c|c|}
\hline \multirow{2}{*}{ Component } & \multicolumn{3}{|c|}{ Initial Eigenvalues } \\
\cline { 2 - 4 } & Total & \% of Variance & Cumulative \% \\
\hline PU & 8.83 & 49.07 & 49.07 \\
\hline PEOU & 1.72 & 9.53 & 58.60 \\
\hline C & 1.58 & 8.76 & 67.36 \\
\hline BI & 1.34 & 7.43 & 74.78 \\
\hline PFC & .94 & 5.22 & 80.01 \\
\hline T & .62 & 3.43 & 83.43 \\
\hline
\end{tabular}

Promax with Kaiser Normalization is the rotation method applied in our research. According to the aforementioned theoretical model, there were six factors measured by 18 items. Therefore, our research fixed the number of factors before the rotation. As Trust and Perceived financial cost were excluded, the remaining 13 items were rotated into 4 factors. The rotation results are presented in Table 2.

3. Rerun of confirmatory factor analysis (CFA) for four-factor model

After eliminating PFC and T, we conducted CFA in a new model. The ratio of Chi-square to degrees of freedom $(\chi 2 /$ d.f $)$ is $4.71(\leq 5)$. The value of GFI (0.90), NFI (0.93), and NNFI (0.93) is all no less than 0.9; that of CFI 
(0.95) is greater than 0.9; and that of the RMSR is $0.07(<0.1)$. Only one index RMSEA (0.10), is slightly out of the suggested ranges. Thus, as in the former model, there is a satisfactory fit between the data and the 4-factor model.

In the new model, for each construct, CR is greater than 0.8; AVE exceeds 0.5, and item loading $(\lambda)$ is greater than 0.7 except for PEOU 4's $(\lambda=0.61)$. However, it is still above threshold limit of 0.5 and thus satisfactory (Chen and Tsai, 2007). Moreover, all item loadings are significant at the level of 0.01. Therefore, this new model indicates the high level of convergent validity. AVE values of C, PU, PEOU and BI (0.76, 0.81, 0.65 and 0.83 respectively) are greater than their maximum square correlation with other constructs. Hence, the discriminant validity of the 4-factor model is considered as acceptable.

\section{Analysis of the structural model}

In order to test 5 hypotheses $(\mathrm{H} 2, \mathrm{H} 3, \mathrm{H} 4, \mathrm{H} 5$, and $\mathrm{H} 6)$, we examined the path coefficients of the structural model. In the undermentioned result, beta $(\beta)$ means structural coefficients relating latent-dependent variable to latent-dependent variable, and gamma $(\gamma)$ means structural coefficients relating latent-independent variable to latent-dependent variable. The figure 2 demonstrates the structural relationships among the research variables and the standardized path coefficient.

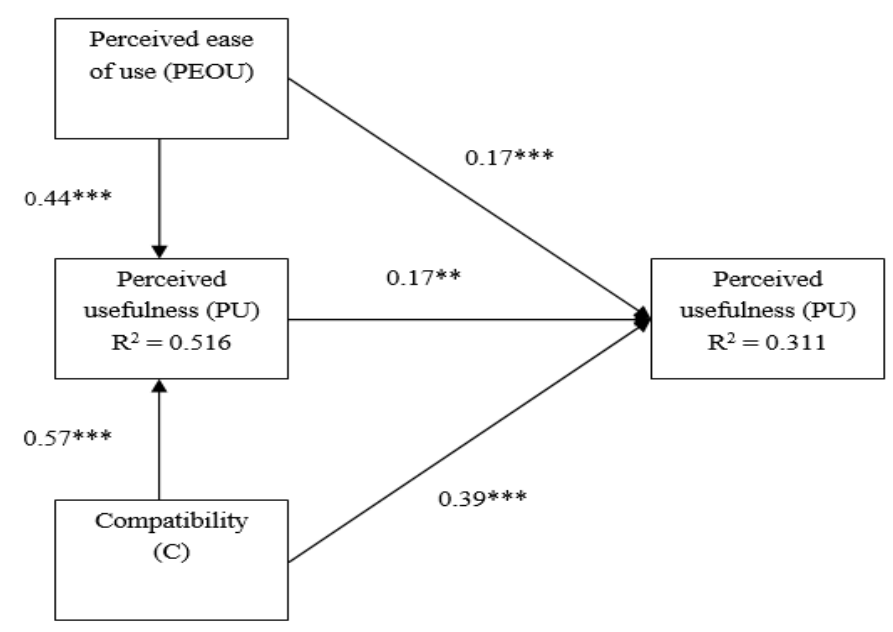

Figure 2. Standardized solution of the structural model. Number on path: standardized coefficient; $R^{2}$ : coefficient of determination, $* P<0.05$, **P $<0.01$

The collected data imply that compatibility has a positive impact on both behavioral intention to use $(\gamma=0.39, \mathrm{P}$ $<0.01)$ and perceived usefulness $(\gamma=0.57, \mathrm{P}<0.01)$. This means that $\mathrm{H} 2$ and $\mathrm{H} 3$ are supported. Perceived usefulness has a positive impact on the behavioral intention to use $(\beta=0.17, \mathrm{P}<0.05)$. Hence, H4 is supported. Perceived ease of use also has a positive effect on both perceived usefulness $(\gamma=0.44, \mathrm{P}<0.01)$ and behavioral intention to use $(\gamma=0.17, \mathrm{P}<0.05)$. Therefore, $\mathrm{H} 5$ and $\mathrm{H} 6$ are supported.

The data also show that the proportion of variance in perceived usefulness explained by perceived ease of use and compatibility is $51 \%$ while the proportion of variance in behavioral intention to use explained by other factors is $31 \%$.

\section{Discussions}

The substantial gap between the number of public and private hospitals surveyed (24 out of 25 surveyed hospitals are public hospitals) explains why PFC is not included in the model. Most of the operating costs in 
public hospitals are state -funded. ELIS is also not financed by the medical staff. Therefore, medical staff do not pay much attention to the cost when they consider using ELIS. One possible explanation for the absence of trust in the model is that most of the respondents do not acquire sufficient technical knowledge. As they are unable to form any expectation about the effects of ELIS or to assess its performance, trust is hardly established among medical staff prior to using ELIS. Therefore, trust may play no significant role in one's intention to use ELIS.

This study has overcome some previous studies' limitations. Firstly, this study has changed the gender characteristics of the sample. Tung et al. (2008) studied the intention to use ELIS of female respondents only. We have expanded the observation onto men and women at the rate of $66.77 \%$ and $33.23 \%$ respectively. This is more relevant to the context of Vietnam where the usage of ELIS is distributed to both men and women. Secondly, compared to the study by Tung et al. (2008), this study added a survey on the applicability of ELIS in hospitals. As a result, we examined the system usage frequency and the level of modernity of the system within the sample. This gives a more accurate overview of the current system usage status. Thirdly, this paper broadened the scope of the research, examining both the public and private sector. Finally, we extracted a new model from the collected data since the extension model of Tung (2008) is found unsuitable in Vietnam situation. The four-factor model which includes PU, PEOU, C and BI is more appropriate than the six - factor model proposed by Tung et al (2008). We found that, relationships between the constructs in this new model were all consistent with previous studies. This finding may assist decision makers in determining strategies to develop and implement ELIS in Vietnamese hospitals.

However, with limited human resources, financial resources and time, this research might not solve all problems. The study has four limitations. Firstly, this study focuses mainly on public hospitals and only one hospital surveyed was a private hospital. Intention to use ELIS between public and private hospitals' employees may have differences. Private hospitals operates on the profit margin generated from revenues, thus pay more attention to cost issues in the installation and the use of ELIS while public hospitals are funded by government. Therefore, the results won't help predict behavioral intentions of medical workers in a private hospital seeking to deploy ELIS. Secondly, the sample size of 25 hospitals is small compared to the overall population, accounting only $3.95 \%$ of total 648 hospitals of North and Central Vietnam. Thirdly, the observation are carried out on different type of medical workers including physicians, nurses, technicians and administrative staffs. Results put into model has gathered all type of workers. According to Melas et al. (2011), different positions with different job characteristics in hospitals shows that the effect between variables in TAM varies. Specifically, each type of medical worker has their own extent of PU and PEOU. We ignored these differences to facilitate the collection process of the survey. Therefore, the accuracy of results placed on each type of medical worker might be impaired. Fourthly, the observation was mainly conducted in hospitals where the level of application of ELIS was quite low. Most of the medical workers there haven't accessed to the modern system, so their perceptions of compatibility, usefulness, ease of use, trust and cost might be different to workers in hospitals with higher levels of ELIS application. Results might precisely reflect real situation of low ELIS application in Vietnam but might not accurately predict the intention to use ELIS in the context of high promotion of modern ELIS and paperless hospitals trend.

\section{Conclusion}

To enhance this subject, we suggest some potential research directions in the future. This study shows that TAM and DOI are highly applicable in the context of Vietnamese healthcare sector, and that trust and perceived financial cost are not relevant. Further studies could extend TAM and DOI with other theories and external variables rather than re-examining trust and perceived financial cost in Vietnamese hospitals. Further studies could also allocate resources to expand sample size or widen study area into Southern Vietnam for more reliable data. Additionally, future research should be conducted on each type of hospitals' workers in order to clearly identify impact of variables on their acceptance of information technology. It is also important that research be undertaken in hospitals with high levels of ELIS application, so that the results could be more highly reflective 
of the current trend in paperless hospitals. However, these findings might be inappropriate in other sectors such as electronic banking, electronic commerce and e-government services. Other studies could re-examine impact of trust and perceived financial cost in such sectors to draw comparison among different sectors in Vietnam.

\section{References}

Agarwal, R. and Karahanna, E., 2000, Time flies when you're having fun: cognitive absorption àn beliefs about information technology usage. MIS Quart, 24 (4), 665-694.

Agarwal, R. and Prasad, J., 1998, Conceptual and operational definition of personal innovativeness in the domain of information technology. Information Systems Research, 9 (2), 204-215.

Bolt, M. A., 1999, Chapter 6: Statistical analysis. In The Social Cognitive Model for Computer Training: An Experimental Investigation. The Faculty of the Virginia Polytechnic Institute and State University. (Blacksburg, Virginia: Doctoral Dissertations), pp. 55-106.

Boomsma, A., 1983, On the robustness of LISREL (maximum likelihood estimation) against small sample size and nonnormality. Unpublished doctoral dissertation, University of Groningen.

Burt, T., 2006, Seeing the future: innovative supply chain management strategies. Healthcare Executive, 2 (1), 16-21.

Chen, C. F. and Tsai, D.-C, 2007, How destination image and evaluative factors affect behavioral intentions? Tourism Management, 28 (4), 1115-1122.

Chen, L.-d., Gillenson, M. L. and Sherrel, D. L., 2002, Enticing online consumers: an extended technology acceptance perspective. Information \& Management, 39 (8), 705-719.

Child, D., 1990, The essentials of factor analysis. 2nd ed. (London, U.K.: Cassell Educational Ltd).

Chin, T., 2003a, Five obstacles to e-prescribing. American Medical News. 46 (18), 17.

Chin, T., 2003b, Incentives lower costs for e-prescribing. American Medical News, 46 (44), 16.

Chuttur, M., 2009, Overview of the Technology Acceptance Model: Origins, Developments and Future Directions. Sprouts: Working Papers on Information Systems, 9(37), 1-22.

Davis, F.D., 1985, A technology acceptance model for empirically testing new end-user information systems: theory and results. Unpulished Doctoral dissertation, MIT Sloan School of Management, Massachusetts, U.S., December, pp. 1-219.

Doney, P. M., Cannon, J. P., and Mullen, M. R., 1998, Understanding the Infuence of National Culture on the Development of Trust. Academy of Management Review, 23 (3), 601-620.

Fishbein, M. and Ajzen, I., 1975, Belief, attitude, intention and behavior: an introduction to theory and research. (Reading, M.A. : Addison-Wesley).

Fornell, C. and Larcker, D. F., 1981, Evaluating structural equation models with unobservable variables and measurement error. Journal of Marketing Research, 18 (1), 39-50.

Furr, R., 2011, Confirmatory Factor Analysis. In The SAGE library of methods in social and personality psychology. Scale construction and psychometrics for social and personality psychology (Thousand Oaks, CA: Sage Publications Ltd), pp. 91-110.

Ganesan, S., 1994, Determinants of Long-Term Orientation in Buyer-Seller Relationships. Journal of Marketing, 58 (2), 1-19.

Garbarino, E. and Johnson, M. S., 1999, The different roles of satisfaction, trust, and commitment in customer relationships. Journal of Marketing, 63 (2), 70-87.

Gefen, D., 2004, What Makes an ERP Implementation Relationship Worthwhile: Linking Trust Mechanisms and ERP Usefulness. Journal of Management Information Systems, Volume 21 (1), 263-288.

Gefen, D., Karahanna, E., and Straub, D. W., 2003a, Inexperience and ExperienceWith Online Stores: The Importance of TAM and Trust. IEEE TRANSACTIONS ON ENGINEERING MANAGEMENT, 50 (3), 307-321.

Gefen, D., Karahanna, E., and Straub, D. W., 2003b, Trust and TAM in Online Shopping: An intergrated model. MIS Quarterly, 27, 51-90.

Grabner-Kraeuter, S., 2002, The role of consumers' trust in online-shopping. Journal of Business Ethics, 39 (12), 43-50. 
Hair, Joseph F., Black W.C, Babin B.J., 2009, Multivariate Data Analysis: A Global Perspective. 7th ed. (New Jersey, U.S.: Upper Saddle River: Prentice Hall)

Holden, R. J. and Karsh, B.-T., 2010. The Technology Acceptance Model: Its past and its future in health care. Journal of Biomedical Informatics: Methodological Review, Issue 43, pp. 159-163

Horan, T. A., Tulu, B., Hilton, B., and Burton, J., 2004, Use of Online Systems In Clinical Medical Assessments: An Analysis od Physician Acceptance of Online Disability Evaluation Systems. Proceedings if the 37th Hawaii International Conference in System Sciences. Hawaii, U.S., pp. 1-10.

Hwang, J., Cho, Y., and Nguyen, L. V., 2009, Investigation of factors affecting the diffusion of mobile telephone services: An empirical analysis for Vietnam. Telecommunications Policy, 33 (9), 534-543.

Johns, P. M., 1997, Integrating information systems and health care. Logistics Information Management, 10 (4), $140-145$.

Karahanna, E., Straub, D. W., and Chervany, N. L., 1999, Information technology adoption across time: a crosssectional comparison of pre-adoption and post-adoption beliefs. MIS Quarterly, 23 (2), 183-213.

Khanh, N. T. V. and Gim, G., 2014, Factors influencing mobile-learning adoption intention: An empirical investigation in high education. Journal of Social Sciences, 10 (2), 51-62.

Lam, D., Boymal, J., and Martin, B., 2004, Internet diffusion in Vietnam. Technology in Society, 26, 39-50.

Landry, S. and Philippe, R., 2004, How Logistics Can Service Healthcare. Supply Chain Forum: An International Journal, 5(2), 24-30.

Langley, C. J. J., Carlisle, D. P., Probst, S. B, Biggs, D. F., and Cail, R. E., 1995, Microcomputers as a logistics information strategy. International Journal of Physical Distribution \& Logistics Management, 25 (4), 61-72.

Lee, Y., Kozar, K. A., and Larsen, K. R. T., 2003, The technology acceptance model: past, present, and future. Communications of the Association for Information Sysytems, 12(50), 752-780.

Lu, Y.-C., Xiao, Y., Sears, A., and Jacko, J. A., 2005, A review and a framework of handheld computer adoption in healthcare. International Journal of Medical Informatics, 74 (5), 410-420.

Luarn, P. and Lin, H.-H., 2005, Toward an understanding of the behavioral intention to use mobile banking. Computers in Human Behavior, 21 (6), 873-891.

MacCallum, R. C., Browne, M. W., and Sugawara, H. M., 1996, Power analysis and determination of sample size for covariance structure modeling. Psychological Methods, 1(2), 130-149.

MacCallum, R. C., Browne, M. W., and Sugawara, H. W., 1996, Power analysis and determination of sample size for covariance structure modeling. Psychological Methods, 1 (2) 130-149.

Mathieson, K., Peacock, E., and Chin, W. W., 2001, Extending the Technology Acceptance Model: the influence of perceived users resources. ACM SIGMIS, 32 (3), 86-112.

Melas, C. D., Zampetakis, L. A., Dimopoulou, A. and Moustakis, V., 2011, Modeling the acceptance of clinical information systems among hospital. Journal of Biomedical Informatics, 44 (4), 553-564.

Moore, G. C. And Benbasat, I., 1991, Development of an Instrument to Measure the Perceptions of Adopting an Infromation Technology Innovation. Information Systems Research, 2(3), 173-239.

Morgan, R. M. and Hunt, S. D., 1994, The Commitment-Trust Theory of Relationship Marketing. Journal of Marketing, 58 (3), 20-38.

Nguyen, L., Nguyen, T. D., and Singh, T., 2014, Effect of Trust on Customer Intention to use Electronic Banking in Vietnam. Proceedings of Global Business and Finance Research Confference, Melbourne, Australia, May, pp. 1-24.

Nunnally, J. C., 1978, Psychometric theory. 2nd ed. (New York, U.S.: McGraw-Hill ).

Paré, G. and Trudel, M.-C., 2007, Knowledge barriers to PACS adoption and implementation in hospitals. International Journal of Medical Informatics, 76 (1), 22-33.

Pavlou, P. A., 2003, Consumer Acceptance of Electronic Commerce: Integrating Trust and Risk with the Technology Acceptance Model. International Journal of Electronic Commerce, Volume 7 (3), 101-134.

Pett, M. L., 2003, Making Sense of Factor Analysis: The Use of Factor Analysis for Instrument Development in Health Care Research. (Thousand Oaks, London, New Delhi: SAGE Publications).

Pett, M. L.,2003, Making Sense of Factor Analysis: The Use of Factor Analysis for Instrument Development in Health Care Research. (Thousand Oaks, U.S: SAGE Publications.) 
Plsek, P. E. and Greenhalgh, T., 2001, The challenge of complexity in health care. Complexity Science, 324 (7313), 625-628.

Poulin, E., 2003, Benchmarking the hospital logistics process: a potential cure for the ailing healthcare sector. CMA Management, Volume 77, pp. 20-4.

Protil, R. M., Duclós, L. C. \& Moreira, V. R., 2002, Logistics Information Systems in hospitals: A case study in Brazil. s.l., Pontifícia Universidade Católica do Paraná, Brazil.

Rogers, E. M., 1962, Diffusion of Innovations (New York, U.S.: Free Press of Glencoe).

Rogers, E. M., 1983, Diffusion of Innovations. 3rd ed. (New York, U.S.: Free Press).

Rogers, E. M., 1995, Diffusion of Innovations. 4th ed. (New York, U.S.: Free Press).

Rutner, S. M., Gibson, B. J., and Williams, S. R., 2003, The impacts of the integrated logistics systems on electronic commerce and enterprise resource planning systems. Transportation Research Part E: Logistics and Transportation Review, 39 (2), 83-93.

Saeed, K. A., Hwang, Y. and Yi, M. Y., 2003, Toward an integrative framework for online consumer behavior research: a meta-analysis approach. Journal of Organizational and End User Computing, 15 (4), 1-26.

Smith, A. D., 2006, Barriers to accepting e-prescribing in the USA. International Journal of Health Care, 19 (2) , 158-180.

Smith, A. D., Manna D. R., 2004, Exploring the trust factor in e-medicine. Online Information Review, 28 (5), 346-355.

Suhr, D. D., 2006, Exploratory or Confirmatory Factor Analysis?, 66-76.

Taylor, S. and Todd, P. A., 1995, Understanding Information Technology Usage: A Test of Competing Models. Information Systems Research, 6 (2), 144-176.

Tornatzky, L. G. and Klein, K. J., 1982, Innovation Characteristics and Innovation Adoption-Implementation: A Meta-Analysis of Findings. IEEE Transactions on Engineering Management, EM-29 (1), 28-45.

Tung, F.-C., Chang, S.-C. \& Chou, C.-M., 2008, An extension of trust and TAM model with IDT in the adoption of the electronic logistics information system in HIS in the medical industry. International Journal of Medical Informatics 77 (2008), pp. 324-335.

Venkatesh V. and Davis F. D., 1996, A Model of the Antecedents of Perceived Ease of Use: Development and Test. Decision Science, 27 (3), 451-481.

Venkatesh V. and Davis F. D., 2000, A Theoretical Extension of the Technology Acceptance Model: Four Longitudinal Field Studies. Management Sciences. 46 (2). 186-204.

Venkatesh, V., Morris, M. G., Davis, G., and Davis, F. D., 2003, User acceptance of information technology: toward a unified view. MIS quarterly: Management information systems, 27 (3), 425-478.

West, S., Finch, J., and Curran, P., 1995, Structural equation models with non normal data variables: problems and remedies. In H. RH (Ed.), Structural equation modeling: concepts, issues, and applications. (London, U.K.: Sage), pp. 56-75.

Wheaton, B., Muthén, B., Alwin, D., and Summers, G., 1977, Assessing Reliability and Stability in Panel Models. Sociological Methodology, 8, 84-136.

Williams, B., Brown, T., and Onsman, A., 2010, Exploratory factor analysis: A five-step guide for novices. Australasian Journal of Paramedicine, 8(3), 1-13.

WORLD INTERNET USAGE AND POPULATION STATISTICS, Date of access: 01/07/2018 https://www.internetworldstats.com/stats.htm

Wu, I.-L. and Chen, J.-L., 2005, An extension of Trust and TAM model with TPB in the initial adoption of online tax: An empirical study. International Journal of Human-Computer Studies, 62 (6), 784-808.

$\mathrm{Wu}$, J.-H. and Wang, S.-C., 2005, What drives mobile commerce? An empirical evaluation of the revised technology acceptance model. Information \& Management, 42 (5), 719-729.

Wu, J.-H., Wang, S.-C. and Lin, L.-M., 2007, Mobile computing acceptance factors in the healthcare industry: A structural equation model. International Journal of Medical Informatics, 76 (1), 66-77. 